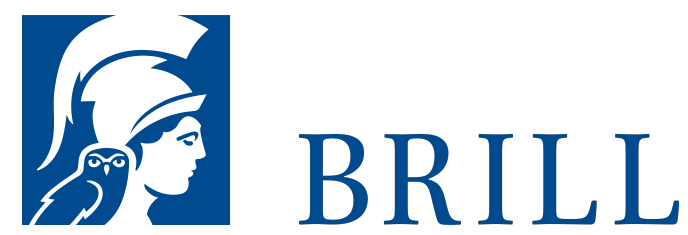

\section{Medizin und Technik}

Risiken und Folgen technologischen Fortschritts

Author: Florian Steger

Moderne Wissenschaft und Technik haben unseren

Handlungsspielraum enorm erweitert, wie die breite öffentliche Diskussion um die Pränataldiagnostik exemplarisch zeigt. Die Folgen technologischen Fortschritts fordern, unser eigenes Verhalten an bestimmten ethischen Standards auszurichten. Einen Beitrag zur,Vergewisserung' leisten die Ethikkommission „Sichere Energieversorgung“, die in Zeiten katastrophaler Unfälle wie 2011 in Fukushima (Japan) von tagesaktueller Bedeutung ist, sowie die Forschungsethikkommissionen und die Klinischen Ethikkomitees, die den verantwortungsvollen Umgang im Rahmen medizinischer Forschung und Versorgung regeln sollen. Medizin und Technik spannen hier einen weiten thematischen Bogen; man denke nur an die Risiken der Intensivmedizin sowie die Risikoabschätzungen im aktuellen Forschungsfeld der synthetischen Biologie. Generell stellt sich betrachtet man die Möglichkeiten des technologischen Fortschritts, sei es im Feld der Atomenergie, im Feld der Gentechnik oder allgemein im Feld der praktischen Medizin die Frage nach einer risikolosen Medizin und Technik. Im vorliegenden Band, der an Band 1 „Praxisfelder angewandter Ethik" anschließt, werden die Ergebnisse eines Workshops der AG „Ethik in der Praxis“ der Jungen Akademie (Berlin) präsentiert.

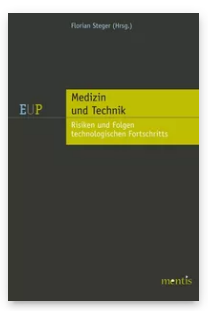

Pages: 248

Seiten

Language:

German

Subjects:

General,

Philosophy

Publisher: Brill | mentis

E-Book (PDF)

Released online:

o4 Oct 2013

ISBN: $978-3^{-}$

89785-957-9

List price

Paperback

Publication date:

o4 Oct 2013

ISBN: 978-3-

89785-787-2

List price 
For more information see brill.com

Order information: Order online at brill.com +44330 333 0049 | customerservices@brill.com Submission information: brill.com/authors

Titles published by Brill | Fink, Brill | mentis or Brill | Schöningh: +49(o)715413279216| brill@brocom.de 